\title{
NARRACIÓN Y SABOTAJE \\ EN LAS BABAS DEL DIABLO Y BLOW UP
}

\author{
NARRATION AND SABOTAGE IN \\ LAS BABAS DEL DIABLO AND BLOWUP
}

María Paz CEPEDELLO MORENO

Ana MELENDO CRUZ

Universidad de Córdoba
fe2cemom@uco.es
aalmecra@uco.es

Resumen: El propósito de este trabajo es demostrar que M. Antonioni y J. Cortázar - en Blow up y Las babas del diablo, respectivamente - comparten los mismos presupuestos teóricos sobre los modos de representación del arte y sus posibilidades de captar la realidad.

Abstract: The aim of this study is to show that M. Antonioni and J. Cortázar -in Blow up and Las babas del diablo - share the same theoretical assumptions on the ways of representation of the art and his possibilities of catching the reality. 
Palabras clave: Ficción. Realidad. Representación. Arte. J. Cortázar. M. Antonioni.

Key Words: Fiction. Reality. Representation. Art. J. Cortázar. M. Antonioni.

Nunca se sabrá cuál es el modo adecuado de abordar un estudio que pretenda analizar unos universos ficcionales y modos discursivos tan singulares como los creados por Cortázar y Antonioni y, menos aún, si estos han de ser puestos en relación. Que el cineasta ferrarés tomó como texto inspirador de su vanagloriada Blow up el famoso relato del escritor argentino de inquietante título, Las babas del diablo, es algo consabido y reconocido en los mismos créditos del filme. Sin embargo, no es menos cierto que la vinculación de ambos relatos se ha limitado, en la mayor parte de los estudios, a señalar una débil relación temática cifrada, casi exclusivamente, en la anécdota de una fotografía clandestina tomada en un parque. El propósito de este trabajo es demostrar que lo que llevó a Antonioni a elegir el cuento de Cortázar va mucho más allá de un episodio casi satélite del relato literario y que ambos creadores comparten los mismos presupuestos teóricos sobre los modos de representación del arte y sus posibilidades de captar la realidad.

\section{NUNCA SE SABRÁ CÓMO HAY QUE CONTAR ESTO}

Deconstrucción y ambigüedad son dos palabras que le resultan especialmente gratas al discurso orquestado por Julio Cortázar en Las babas del diablo. Deconstrucción, en el sentido de sabotaje ${ }^{1}$, porque dinamita algunos sólidos conceptos en los que han estado sustentados tradicionalmente los mecanismos de la ficción y del discurso narrativo y ambigüedad en tanto ausencia de una única lectura a la que el relato debería conducirnos inexorablemente. Desde la primera línea, el lector se encuentra ante una incertidumbre que recorre todo el discurso y que se irá acrecentando a medida que éste avanza: la dificultad para representar la realidad a través del arte y los artificiosos mecanismos para intentar conseguirlo. Señala Pozuelo Yvancos

${ }^{1}$ Utilizamos el concepto de sabotaje en el sentido en que ha sido definido recientemente por Manuel Asensi en su libro Crítica y sabotaje cuando dice que «un texto literario puede ejercer una acción saboteadora en el seno de los sistemas modelizadores dominantes» (2011:252). 
(1993: 228), en su lúcido estudio sobre el relato de Cortázar en Poética de la ficción, que:

Este cuento puede actuar como ejemplo de una poderosa veta especulativa que la modernidad artístico-literaria [...] ha explotado: contemplar el arte a la luz de sus materiales y en la frontera de la discusión de su legitimidad frente al mundo que pretende «representar».

Para conseguir semejante empeño el autor pone en funcionamiento esos procesos saboteadores, generadores de ambigüiedad, de los que hablábamos más arriba y que ha dado lugar a múltiples lecturas e interpretaciones. El comienzo, en forma impersonal, ya nos está disponiendo ante un discurso que se presenta problemático en tanto no es posible encuadrarlo dentro de los límites de los conceptos narratológicos aprehendidos en la «narración realista»: «Nunca se sabrá cómo hay que contar esto, si en primera persona o en segunda, usando la tercera del plural o inventando continuamente formas que no servirán de nada»(p. 67) ${ }^{2}$.

Intentar responder a las clásicas preguntas sobre las que se sustenta todo relato tales como ¿quién cuenta la historia? o ¿desde qué punto de vista se cuenta la historia? resulta todo un desafío en el texto compuesto por Cortázar en tanto el autor se propone y consigue la desarticulación de las categorías de autor, narrador, voz o punto de vista. Los vaivenes entre la heterodiégesis y la homodiégesis, la alternancia de las personas gramaticales o la presencia de agentes narradores inertes que se independizan del dominio humano ofrecen al lector un espacio discursivo inestable e inasible donde las posibilidades de interpretación se multiplican en solución de continuidad:

Puestos a contar, si se pudiera ir a beber un bock por ahí y que la máquina siguiera sola (porque escribo a máquina) sería la perfección. Y no es un modo de decir. La perfección, sí, porque aquí el agujero que hay que contar es también una máquina (de otra especie, una Contax 1. 1. 2) y a lo mejor puede ser que una máquina sepa más de otra máquina que yo, tú, ella —la mujer rubia-y las nubes (p. 67).

El protagonista comienza cuestionando la propia capacidad de la escritura literaria, que él mismo está intentado llevar a cabo, para representar la realidad así como la de la fotografía, más aún, del arte en general. Se pone ante

${ }^{2}$ Citamos por la edición del cuento en el volumen Las armas secretas (Cortázar, 2005). Daremos número de página, tras la cita, según esta edición. 
nuestros ojos de lectores, sin disimulos, el artificio de la ficción de manera que se da lugar a una historia entrecortada constantemente por las reflexiones de un autor-narrador que no tiene dominio sobre el propio universo construido, que está muerto en tanto hacedor literario y cuya interpretación de lo narrado no es fiable, no es unívoca, es incierta:

Entonces tengo que escribir. Uno de todos nosotros tiene que escribir, si es que todo esto va a ser contado. Mejor que sea yo que estoy muerto, que estoy menos comprometido que el resto; yo que no veo más que las nubes y puedo pensar sin distraerme, escribir sin distraerme (ahí pasa otra, con un borde gris) y acordarme sin distraerme, yo que estoy muerto (y vivo, no se trata de engañar a nadie, ya se verá cuando llegue el momento, porque de alguna manera tengo que arrancar y he empezado por esta punta, la de atrás, la del comienzo, que al fin y al cabo es la mejor de las puntas cuando se quiere contar algo) (pp. 67-68).

Estamos ante lo que Darío Villanueva (2006: 33), partiendo de la filosofía kantiana, denominaría relato fenoménico, puesto que es un texto que se justifica como un fenómeno resultante de un proceso de producción cuyas circunstancias son explicitadas. Pero Cortázar va un paso más allá porque Las babas del diablo carece de la fiabilidad que caracteriza a la instancia intermedia entre el texto y los lectores de las narraciones fenoménicas. A ello contribuye, además de la propia caracterización ambigua del que escribe - recordemos que está vivo y muerto - , la inconsistencia del narrador y el punto de vista que adopta para narrar los hechos que necesita contar.

La alternancia de voces - heterodiégesis y homodiégesis - , de personas gramaticales - primera del singular, tercera del singular, primera del plural - y de puntos de vista - de focalización interna a focalización externaimpide identificar al narrador y su visión de los hechos exclusivamente con Roberto Michel y su óptica personalísima de lo relatado en Las babas del diablo. Muy al contrario, estos vaivenes generan una polifonía textual, en términos de Bajtín (1986: 16) ${ }^{3}$, que, como advierte el gran teórico literario, implica una heterofonía o diversidad de voces, una heteroglosia o distintos niveles de lengua y una heterología o diferentes tipos de discursos que acarrea una multiplicidad de visiones e interpretaciones de la realidad. Estas «bifur-

\footnotetext{
${ }^{3}$ Otro concepto bajtiniano que hace acto de presencia en el texto de Cortázar es el de cronotopo en fragmentos como el que sigue: «Y ya que vamos a contarlo pongamos un poco de orden, bajemos por la escalera de esta casa hasta el domingo 7 de noviembre, justo un mes atrás. Uno baja cinco pisos y ya está en el domingo» (p. 68).
} 
caciones» ponen de manifiesto la complejidad de un enunciador del discurso que integra al personaje de Roberto Michel que «cuenta» pero también a la máquina de escribir, esa Remintong que se nombra al principio, y, muy especialmente, a la máquina de fotos, la Contax 1. 1. 2., lo que lleva implícito la duplicidad de voces pero también la de miradas. La actividad de la escritura y la de la fotografía se identifican.

En la primera parte del cuento tenemos acceso a la historia narrada por un escritor, quien, gracias a la realización de una fotografía, interviene en un suceso que, según su interpretación, podría haber tenido trágicas consecuencias, y se vale de la palabra escrita - aquellas palabras que salen de su Remintong - para contarlo. Hasta ese momento, la fotografía sólo ha sido un instrumento más, un objeto inerte, inscrito en el relato, que forma parte del devenir de la historia. Sin embargo, en la segunda parte de Las babas del diablo tiene lugar un hecho insólito, un hecho revelador, que no sólo es atrapado por la máquina de escribir, sino por la autonomía que Cortázar otorga a la imagen como lenguaje expresivo, como fuerza liberadora y mostración de una posible verdad. Esto tiene lugar en el instante en que Michel, tras ampliar varias veces la fotografía que unos días antes había tomado en la Isla de Saint-Louis, se sitúa frente a ella, ocupando el lugar adoptado por el objetivo de la cámara en el momento de realizar dicha fotografía. Se produce entonces un proceso de metamorfosis o de cambio, en el que el protagonista suplanta el objetivo de la Contax 1. 1. 2., o, más bien, el objetivo de la máquina fotográfica parece devorar, al propio Michel, quien, inmóvil, observa cómo aquella escena que quedó fijada en el papel fotográfico, aquella huella literal del referente comienza a cobrar vida; pero lo ve desde fuera, como si el marco en el interior del cual se sitúa la imagen, se tratara de una gran pantalla de cine. Es, entonces, cuando un ojo mecánico, el de la cámara fotográfica, o más bien cinematográfica - al fin y al cabo las imágenes adquieren temporalidad y movimiento - suplanta al ojo humano de Michel; la cámara devora al hombre convirtiéndose de este modo en testigo y narrador del suceso acontecido:

De pronto el orden se invertía, ellos estaban vivos, moviéndose, decidían y eran decididos, iban a su futuro; $y$ yo desde este lado, prisionero de otro tiempo, de una habitación en un quinto piso, de no saber quiénes eran esa mujer y ese hombre y ese niño, de ser nada más que la lente de mi cámara, algo rígido, incapaz de intervención (p. 82).

Como explica Albarracín Sarmiento (1995: 94), los hechos, la historia se independiza del narrador y se representa por sí misma. La cámara fo-cine- 
matográfica es introducida en el universo literario para ocupar la posición del narrador/observador con la finalidad de capturar el instante, de atrapar el gesto revelador, la visión que todo lo resume y, al mismo tiempo, para convertir a Michel en destinatario de una obra creada por él mismo, en la medida en que los protagonistas de la escena que quedó atrapada aquella mañana de domingo interpelan al fotógrafo-espectador tras cobrar vida y trasgredir así las normas, la objetividad y la verdad inmanente que se le supone a la imagen fotográfica. De este modo, Cortázar introduce en el texto literario instancias propias de otras manifestaciones artísticas también para sabotearlas: la fotografía que cobra vida y sus personajes que traspasan el espacio de lo ficcional para interpelar a Michel que ha quedado fuera del espacio fo-cinematográfico por él creado. Y es que estas interpelaciones, en palabras de Casetti, son:

Un intento indebido de invadir un espacio separado, porque es una ruptura de una trama que hay que guardar intacta, las miradas a la cámara se perciben como infracción de un orden canónico, como atentado a un buen funcionamiento, de una representación o de una narración fílmica (1996: 40).

Y aún profundiza más el escritor argentino en esta deconstrucción de las estructuras narrativas que acontece en Las babas del diablo en la medida en que, de igual modo que los personajes de la imagen en movimiento se dirigen al espectador que es Roberto, éste interviene desde el otro lado de la ficción fo-cinematográfica en el desenlace de la escena al ocasionar con su grito que el chico huya:

Creo que grité, que grité terriblemente, y que en ese mismo segundo supe que empezaba a acercarme, diez centímetros, un paso, otro paso, el árbol giraba cadenciosamente sus ramas en primer plano, una mancha del petril salía del cuadro, la cara de la mujer, vuelta hacia mí como sorprendida iba creciendo, y entonces giré un poco, quiero decir que la cámara giró un poco, y sin perder de vista a la mujer empezó a acercarse al hombre que me miraba con los agujeros negros que tenía en el sitio de los ojos, entre sorprendido y rabioso miraba queriendo clavarme en el aire, y en ese instante alcancé a ver un gran pájaro fuera de foco que pasaba de un solo vuelo delante de la imagen, y me apoyé en la pared de mi cuarto y fue feliz porque el chico acababa de escaparse, lo veía corriendo, otra vez en foco, huyendo con todo el pelo al viento, aprendiendo por fin a volar sobre la isla, a llegar a la pasarela, a volverse a la ciudad (pp. 82-83).

Es así como Michel, después de haber sido suplantado por la máquina, muere, a manos de la propia historia, quedando del otro lado $-\mathrm{y}$ vive al mis- 
mo tiempo, como él mismo afirma en una de las primeras líneas del relato-. Por tanto, la cámara se convierte en narrador y, así, el conflicto dramático es sustituido por la pura imagen; una imagen vaciada, en la que sólo queda a foco el cielo que servía como fondo a la escena y que está siendo cruzado desde entonces por nubes y pájaros, mientras las salpicaduras de la lluvia resbalan sobre el objetivo, sobre el ojo-máquina, sobre un ojo que llora al revés:

$Y$ luego otra, y a veces en cambio todo se pone gris, todo es una enorme nube, y de pronto restallan las salpicaduras de la lluvia, largo rato se ve llover sobre la imagen, como un llanto al revés, y poco a poco el cuadro se aclara, quizá sale el sol, y otra vez entran las nubes, de a dos, de a tres. Y las palomas, a veces, y uno que otro gorrión (pp. 83-84).

Decíamos al principio que dos de los conceptos que más gratos le resultan al análisis de Las babas del diablo son el de deconstrucción y ambigüedad: deconstrucción del artificio narrativo y ambigüedad en el modo de reconstruir lo acontecido que nos priva de una lectura unívoca. En palabras de Bobes Naves (1991: 311), «con los mismos datos, pueden darse diferentes historias».

\section{NO ES LA HISTORIA DE SIEMPRE...}

En uno de los títulos de crédito con los que comienza Blow up, puede leerse: «Story by Michelangelo Antonioni. Inspired by a short story by Julio Cortázar» (F1). A partir de esta inscripción hemos de entender que el film es deudor del relato del escritor argentino. Algunos estudiosos, como Domènec Font (2003: 181), se refieren a ello, planteando únicamente que la película está basada en el cuento de Cortázar, y otros, como Seymour Chatman (2004: 100), mencionan que es una adaptación. Sin embargo, consideramos que referirnos a Blow up como una mera adaptación del texto de partida, sería quedarnos cortos o no decir prácticamente nada. Nos unimos a la opinión de Pérez Bowie, quien señala que:

La noción de reescritura resulta ser la más rentable para el estudio de las prácticas adaptativas, especialmente de aquéllas que presentan un mayor interés por albergar una opción personal mediante la que el realizador lleva a cabo una auténtica reelaboración del texto de partida proyectando sobre él sus propios intereses ideológicos y estéticos además de las determinaciones derivadas del nuevo contexto en el que se inscribe su creación (2010: 26). 
Desde nuestra perspectiva se hace necesario, para abordar el estudio del trabajo de modelización que Antonioni configura en Blow up con relación a Las babas del diablo, utilizar un concepto propuesto por Lubomir Dolezel (1986: 5-48) para designar los procesos de transmisión dinámica ${ }^{4}$ de que pueden ser objeto las obras literarias: la transducción, concepto desarrollado posteriormente por Jesús G. Maestro (1997: 553-563) o Darío Villanueva (2008: 54). Efectivamente, Antonioni se convierte en transductor de Las babas del diablo y genera un universo fílmico tan singular como el construido en Blow up, ya que, aunque la película del cineasta italiano propone un código hermenéutico que convierte en contenido explícito el problema de la imagen $^{5}$, los presupuestos de partida en cuanto al proceso ilusorio del arte son muy similares.

En todo caso, lo que no ha pasado desapercibido a un maestro de la forma como Michelangelo Antonioni, paradigma de la modernidad cinematográfica, es el complejo diseño narrativo que encierra el cuento del escritor argentino, a lo que cabría añadir que no supone ninguna novedad que el creador ferrarés se preocupe en sus films por el discurso narrativo y reflexione sobre él. De hecho, sería uno de los aspectos a los que habría que atender en la filmografía antonioniana si abordáramos un estudio del contexto paradigmático ${ }^{6}$ de la misma. Un ejemplo claro de ello lo encontramos ya en su primer largometraje, Crónica de un amor (1950), que, de manera motivada, comienza con lo que aparentemente parece una voz en off que informa de que: «No, no es la historia de siempre. No hay ninguna sospecha. En este caso, la mujer es fiel». Decimos aparentemente porque pocos segundos después el espectador puede comprobar que no es así, que el locutor de esas palabras forma parte de la diégesis. Francesco Casetti, en un estudio pormenorizado sobre el diseño narrativo de este film, afirma lo siguiente al respecto:

Bajamos un elemento extra o meta-diegético a componente puramente diegético. El narrador se revela entonces un personaje cualquiera, lejos del privi-

\footnotetext{
${ }^{4}$ Dentro de los procesos de transmisión dinámica se dan cita procedimientos tan diversos como los de intertextualidad, transferencia intercultural, recepción crítica, parodia, readaptaciones, etc.

5 Aunque estamos de acuerdo con esta afirmación de D. Font (2003: 184-185) no compartimos, por el contrario, el punto de vista del estudioso cuando afirma que Blow up se distancia del relato de Cortázar en relación con los códigos hermenéuticos que propone el autor argentino.

${ }^{6}$ Entendemos contexto paradigmático en el sentido en que lo define Santos Zunzunegui en Paisajes de la forma (1994: 125): «Llamo contexto paradigmático al orientado al estudio de los lazos que se detectan entre los elementos fílmicos provenientes de películas diferentes pero pertenecientes a la misma obra unitaria. Se puede mostrar así cómo la significación de esos elementos puede extrapolarse al conjunto del cineasta implicado".
} 
legio de dirigir la narración [...] El narratario se aprovechará rápidamente de este prevalecer de una estructura frente a la otra; este se asomará en el film con los rostros de cualquiera que haga de observador interno a la ficción (1996: 144-146).

De esta forma, el espectador queda entonces excluido o sacado fuera de la historia, enfatizándose así el papel desempeñado por éste que permanece como mero observador de los hechos que van a sucederse en la pantalla. Se pone así de manifiesto, desde el comienzo del filme, un rasgo predominante en ese modelo de representación que, por oposición al modelo de Hollywood, se ha dado en llamar modernidad cinematográfica. Nos estamos refiriendo a la ambigüedad a través de la cual se explicita la enunciación, que aparece en multitud de ocasiones en el cine de Antonioni de las formas más diversas, en este caso referida a las instancias discursivas que se ponen de relieve en el relato. Es preciso recordar aquí que la ambigüedad junto a la deconstrucción es uno de los rasgos con los que hemos definido la articulación del cuento de Cortázar. También en la película podemos hablar claramente de deconstrucción, en el sentido de sabotaje, en tanto Blow up acomete la desarticulación del relato clásico a partir de las citadas instancias discursivas y de la propia entidad de la historia. Y es que un denominador común en el cine del maestro italiano es el hecho de privilegiar la imagen sometiendo a la historia, pero también es cierto que en ningún momento de su filmografía hay un proceso de autorreflexión tan profundo en cuanto a realidad y ficción como el que tiene lugar en el filme, un proceso que, insistimos, resulta igualmente característico de Las babas del diablo.

En Blow up se configura un elaborado discurso narrativo que pone de manifiesto la especificidad del cine en el sentido que muestra su doble registro: icónico y verbal, lo que supone, por razones evidentes, un distanciamiento del texto literario. Obviamente, la imagen cinematográfica constituye un significante de diversa entidad respecto a la palabra, por más que Cortázar preste especial atención a la imagen en su discurso. Por eso, «los relatos fílmicos, como audiovisuales que son, implican la presencia de dos capas superpuestas de narratividad: mostración y narración» (Gaudreault y Jost, 1995: 63-64). En este sentido, habríamos de tener en cuenta la figura del enunciador por ser la instancia depositaria de ambas capas, superpuestas, de narratividad y donde tienen razón de ser los conceptos de observador y $o b$ -

${ }^{7}$ Nótese que Casetti habla ya de la figura del observador en relación al punto de vista, es decir, a la mostración. 
servatorio (Poyato, 2006: 171). Recordemos a tenor de lo dicho que cada personaje en un film tiene su propia voz y que los detalles que han de ser descritos por un narrador en literatura son mostrados visualmente en el discurso fílmico. De esta forma, según explica Pedro Poyato, quien parte de los presupuestos establecidos por Casetti:

Por lo que se refiere a su dimensión visual, el texto filmico despliega de esta guisa los correspondientes lugares de subjetividad: un Yo (enunciador) muestra, hace-ver, a través del observador, a un Tú (enunciatario) que mira, y vehacer, a través del observatario, a un Él (personaje) que actúa; lugares cuyos modos de relación - la forma que cada uno de ellos instaura con los otros dos-dan lugar a las distintas configuraciones que estructuran los discursos fílmicos (2006: 171-172).

Pues bien, desde el comienzo, el discurso de Blow up se sitúa en los parámetros de lectura apuntados por Casetti $(1996: 41,59)$ — «Yo muestro y te hago ver»-, porque ya los títulos de crédito de dicho film, además de informar, como es pertinente, del elenco que ha colaborado en la realización de la película, se presentan como pura imagen discursiva de la que podemos deducir, cuanto menos, la importancia que, desde la enunciación, cobran tres elementos fundamentales en todo el film: el paisaje, la figura y el fondo.

Y es que las letras, impresas sobre el espeso fondo ${ }^{8}$ de hierba que rellena todo el encuadre, se vacían dejando paso a la forma que tras ellas aparece. Sus aristas terminan rasgando el lienzo saturado de color, de manera que es posible vislumbrar los cuerpos femeninos que están siendo fotografiados y que resultan, en parte, seccionados por las propias líneas que los modelan; unos cuerpos que, a su vez, se recortan sobre el cielo azul que les sirve de fondo (F2). En la pantalla aparecen, por tanto, unas palabras que quedan desprovistas de materia, esto es, de contenido, y donde cobra protagonismo la forma ${ }^{9}$. Significantes, al fin, desnudados de su significado originario y rellenos de pura imagen, que se constituyen, así, en un signo distinto. Esta-

\footnotetext{
${ }^{8}$ Entendiendo éste en los términos semióticos apuntados por González Requena (1995: 11) cuando explica que: «El Fondo, por tanto, no es el Paisaje, sino la ausencia de la Figura: comienza allí donde la figura cesa (...) Podríamos decir entonces, que, en tanto la imagen se halla indisociablemente ligada a la Figura, el Fondo es su reverso".

9 Este planteamiento está muy próximo a la corriente «espacialista», iniciada por Lucio Fontana, quien aseguraba que: «El materialismo establecido en todas las conciencias exige un arte en posesión de valores propios, alejado de la representación que hoy constituye una farsa [...] Se requiere un cambio en la esencia y en la forma. Se requiere la superación de la pintura, de la escultura, de la poesía, de la música. Se necesita un arte mayor acorde con las exigencias del espíritu nuevo". En http://descontexto.blogspot.com/2006/11/el-manifiesto-blanco-de-lucio-fontana.html.
} 
mos, pues, ante un discurso que está siendo deconstruido en la medida en que el espacio se revela horadado por la palabra que, a su vez, es invadida por formas para ceder, desde el comienzo del film, el protagonismo a la imagen y conseguir que una instancia enunciadora reflexiva se vaya acomodando en él. Antonioni, en un gesto paradigmático de la modernidad cinematográfica, rasga la superficie plana de la pantalla de cine con el propósito de desvelar las formas que se esconden detrás, aunque estas formas acaben engullidas en la estructura cerrada que enuncia el film. Sólo desde esta perspectiva se puede entender que la figura del protagonista, inscrita en la superficie saturada de verde del penúltimo plano de la película, desaparezca mediante un fundido encadenado (F3), para dejar paso a las letras colmadas de negro, opacas, por tanto, que anuncian el fin de Blow up (F4).

Como sucediera en el cuento de Cortázar, la cámara fotográfica, en ese «mostrar»y «hacer ver», al que nos referíamos con anterioridad, cobra especial relevancia en Blow up. Es por ello por lo que Thomas - el protagonista de la película - desvela la presencia de la cámara que se encuentra en su Rolls Royce, enmascarando esta acción bajo la excusa narrativa de solidarizarse con los mimos vociferantes del comienzo del film (F5).

Aparece, por primera vez, en escena una lente, un ojo artificial, cuya misión consiste en ver para, seguidamente, capturar aquello que ve. La enunciación insiste en el protagonismo de Thomas y su cámara, por medio de un plano picado, en el que se muestra al fotógrafo dirigiéndose a casa en su descapotable y a la pasajera fotográfica que ocupa el asiento trasero del mismo (F6). A partir de este momento, la cámara, aunque no sea la misma siempre, se instaura en términos discursivos como sujeto mediador u observador que «hace ver», entre el enunciador que «muestra», mediante una mirada que no está vinculada a la de ningún personaje de la diégesis, por tanto de ocularización cero, y el observatario que «ve-hacer», de forma que el plano queda anclado en su mirada y se podría hablar de ocularización interna secundaria puesto que, además, esa mirada puede ser deducida del contexto ${ }^{10}$.

${ }^{10}$ Según José Antonio Pérez Bowie (2008: 44-45) «la aplicación más sistemática de esta categoría [el punto de vista] al análisis cinematográfico la llevan a cabo Gaudreault y Jost en su libro conjunto [...] Comienza distinguiendo entre los puntos de vista visual y cognitivo, a los que denominarán respectivamente ocularización y focalización. La ocularización caracteriza la relación entre lo que la cámara muestra y el personaje supuestamente ve. Dentro de ella cabe distinguir entre ocularización cero (la mirada no está vinculada a ningún personaje de la diégesis) y ocularización interna (el plano está anclado en la mirada de un personaje); en esta última distinguen dos posibilidades (primaria o secundaria) según la mirada esté explicitada mediante procedimientos como la imagen borrosa que remite a un miope (...) o sea deducible del contexto". 
Después, el ojo cinematográfico acompaña al fotógrafo y a otra de sus cámaras por el interior de los espacios que configuran la casa-estudio en la que éste vive y desarrolla su trabajo. Es a partir de ahora cuándo el film comienza a dar señales de la particular relación que Antonioni establece entre el enunciador y ese observador de ocularización interna secundaria, el observatario y el enunciatario. Esta relación que, como es de esperar en una escritura moderna como la del cineasta ferrarés, va más allá de transgredir la dialéctica entre el «hacer ver»y el «ver hacer», recala, al igual que lo hace Cortázar, en los modos de representación del arte y en la vinculación del mismo con la realidad. Para dar cuenta de ello, la presencia de la cámara fotográfica se revela fundamental y esta importancia queda reflejada por primera vez en el film, de manera visual, en el momento en que esta aparece mirando, como un ente autónomo e independiente, para después convertirse, literalmente, en el ojo de Thomas. Todo ello sucede en el instante en que, valiéndose de un complicado movimiento de la cámara cinematográfica, el enunciador muestra a la modelo como punto de fuga de la imagen, mientras el protagonista aparece por la izquierda y la cámara fotográfica, apoyada en su trípode, por la derecha del encuadre (F7).

Simultáneamente, con un leve desplazamiento de la cabeza de la cámara cinematográfica hacia arriba y siempre tomando como punto de referencia el vértice del triángulo ocupado por Veruhska ${ }^{11}$, el espectador tiene la sensación de que la cámara fotográfica inicia un movimiento autónomo, ocasionando así en quien recibe tal información visual la ilusión de que es el trípode, en el que se encuentra apoyada, el que desciende y se sitúa a la altura adecuada para iniciar la sesión (F8). A partir de entonces es Thomas, convertido en instrumento del cual se sirve la máquina, quien comienza a disparar fotografías en el lugar seleccionado por ella (F9). Antonioni utiliza esta escena, de gran fuerza visual, para presentar las figuras que van a encarnar las dos instancias fundamentales del discurso fílmico que, además del enunciador, se dan cita en Blow up, a saber, el observador y el observatario en la cámara fotográfica y Thomas, respectivamente. De esta manera, el enunciador se hace presente en el film para dar cuenta de cómo, a través del observador, el observatario puede ver y comunicar su visión, posteriormente, al enunciatario.

${ }^{11}$ Blow up cuenta en su reparto con algunas de las modelos más importantes de la época en la que se realiza el film, Veruhska entre ellas. 


\section{UNA PERCEPCIÓN DE LA REALIDAD LIMITADA Y FALAZ}

$\mathrm{Al}$ analizar Las babas del diablo habíamos constatado que la realidad fotografiada por Roberto Michel en la Isla de Saint-Louis, fijada en un espacio y tiempo concreto gracias a la Contax 1.1.2, no era como él la había creído percibir. Sorprendido e inmovilizado contempla cómo la imagen ampliada cobra vida para mostrarle otra realidad, la realidad que no había conseguido captar su ojo. En Blow up, por su parte, Thomas acude a un parque con un propósito similar al que perseguía el protagonista del cuento de Cortázar. Como éste, fotografía a una pareja que le llama la atención y no es hasta que llega a casa y revela los negativos cuando, tras varias ampliaciones, descubre el cadáver de un hombre. Resulta significativo en este sentido el diálogo que se establece entre el protagonista y la novia de su amigo Bill, el pintor, después de que Thomas se acercara al parque para certificar que el cadáver que había aparecido con el revelado y las sucesivas ampliaciones de la fotografía era real:

THOMAS: Esta mañana he visto a una persona asesinada.

ELLA: ¿Dónde?

THOMAS: De un tiro. En un parque.

ELLA: ¿Estás seguro?

THOMAS: Aún sigue allí.

ELLA: ¿Quién era?

THOMAS: Alguien.

ELLA: ¿Cómo sucedió?

THOMAS: No lo sé, no lo vi.

Ciertamente, Thomas, como Michel, no lo vio, sino que le fue revelado con posterioridad. Fue un ojo mecánico quien tuvo acceso al acontecimiento y lo capturó. El resultado se muestra ambiguo ${ }^{12}$ en ambos relatos, pero de diferente forma. Mientras que la fotografía se revela en el film como huella literal de un referente que es extraído de la realidad, como ve-

12 Decimos ambiguo en el sentido de las palabras de Giorgio Tinazzi (2005: 109) respecto al universo antonioniano: «se pone de manifiesto el carácter de ambigüedad [...] No es tanto una cuestión de objetividad cuanto del valor objetivo del cine como manera de afrontar la realidad. Un esfuerzo por interrogarse que se traduce también en ficción». 
remos seguidamente, Cortázar invierte el orden dotando a la fotografía de vida a la vez que paraliza lo que queda al otro lado de ella, es decir, la realidad dentro del espacio ficcional. Esto sucede en el momento en que, como dice Michel, narrador y protagonista del cuento del escritor argentino - recordémoslo-, «ellos estaban vivos, moviéndose, decidían y eran decididos, iban a su futuro; y yo desde este lado, prisionero de otro tiempo» (p. 82). Por tanto, la palabra, el discurso verbal es sometido, en mayor o menor grado, a un proceso de modelización que a la imagen fo-cinematográfica le es negado. Así lo entiende Philippe Dubois al referirse a ello de la siguiente forma:

Si se admite a menudo con bastante facilidad que el explorador puede fabular relativamente al regreso de sus viajes y así elaborar, por ejemplo para impresionar a su auditorio, relatos más o menos hiperbólicos en los cuales la parte de fantasía y de imaginación son difícilmente despreciables, la fotografía, por el contrario, al menos ante la doxa y el sentido común no puede mentir (1986: 44).

Es más, la fotografía se convierte en la momificación del referente. Pero Cortázar no momifica a los representados en ella, sino que los dota de vida; por el contrario, es aquel que realiza la fotografía quien queda atrapado en el discurso que pone en funcionamiento el autor.

Pues bien, a partir de ese presupuesto que se le supone a la fotografía como fiel imitadora de la realidad, Antonioni reflexiona entre el ver y el percibir, es decir, entre lo que Thomas no es capaz de captar y el ojo mecánico de la cámara sí. Esa forma no-visible que escapa a nuestra percepción, y que la fotografía ha recogido, necesita ser sometida a un proceso de modelización capaz de descubrir aquello que, aunque presente en ella, permanece oculto al ojo. Pero el maestro italiano da una vuelta de tuerca en tanto que Thomas somete el negativo a un proceso de formalización tan agresivo que esa forma última encargada de «revelar» la realidad acaba por convertirse en una imagen abstracta e irreconocible, es decir, «no-visible». De esta forma termina por no mostrar aquello que encierra y, como consecuencia, deja de ser testigo de la realidad que capturó. La imagen deja de tener sentido sin la secuencia lógica de fotografías que la habían precedido; tanto es así que, tras haber perdido su estatuto de transmisora de la realidad, «parece»una pintura abstracta, una creación que tiene que ver más con esos cuadros que aparecen en el film vinculados a Bill, el amigo pintor de Thomas. 
Si Cortázar inventa un álter ego - mitad Cortázar, mitad Larraín ${ }^{13}$ - es decir, mitad escritor y mitad fotógrafo, con la intención de cuestionar, como ya vimos, ciertos aspectos de la escritura y la fotografía, Antonioni, en lugar de diseñar un personaje aparentemente esquizofrénico, desentrañando a través del mismo ciertos entresijos que tienen que ver, en su caso, con la fotografía y la pintura, elabora, en este sentido, un discurso más simple, que no distraiga al espectador de lo que de verdad le importa: fotografía versus pintura, y la ambigüedad que estos dos medios de expresión en cuanto a representación de la realidad generan. Para ello crea dos personajes: Thomas, el fotógrafo, y Bill, el pintor.

Antonioni opta por introducir en Blow up, un tipo de pintura que, a base de puntos cargados de materia, realza precisamente esos valores (F10). Una pintura que deconstruye la representación de la realidad tal y como el ojo la percibe, que reivindica la irreductibilidad del espacio pictórico y su independencia, porque para representar la realidad, o más bien, para mimetizarla, aparentemente, ya existe la fotografía. No obstante, el cineasta, en ese proceso de alquimia al que Thomas somete a la fotografía, la hace caminar por senderos muy parecidos a los recorridos por la pintura, es decir, es a partir de la pérdida de la forma reconocible, cuando el hallazgo comienza a tener sentido. La fotografía rompe con la estricta lógica de la forma para reconocerse a sí misma, para reconocer su identidad en la propia materia que la compone. Es así como Thomas, al igual que Bill, encuentra algo a lo que asirse dentro de ese universo, aparentemente real ${ }^{14}$, que le muestran las fotografías tomadas en el parque. Y lo halla, precisamente, en esa última ampliación, en la única que queda tras el saqueo sufrido en su casa (F11) donde se pierde toda información visual de la escena inicial, «dando paso en cambio a la información intrínseca del propio soporte de la película (el grano, los arañazos, las formas inconexas de blancos y negros). De alguna forma, con ese gesto minimalista se alcanza el grado cero de la inscripción visual, que permite indagar en la composición íntima de las imágenes»(Fontcuberta, 2010: 45).

Es cierto que, desde el punto de vista de la historia, el gesto de Thomas se ve frustrado, puesto que, en esa pérdida de visibilidad, la información que pudiera aportar la fotografía, como testigo de un hecho, queda disuelta.

${ }^{13}$ Recordemos que Cortázar se inspira para escribir su cuento en una fotografía que su amigo Sergio Larraín, toma a escondidas, en la Isla de Saint-Louis de una pareja de enamorados.

14 Afirma Fontcuberta que las imágenes de Blow up, «antológicamente nos dicen que por más real que parezca, cualquier imagen contiene la amenaza de una falsedad inevitable» (2010: 46). 
Pero insistimos en que no es el fin de Michelangelo Antonioni resolver el crimen que ha tenido lugar. Blow up, como Las babas del diablo, nos hace partícipes, más allá del hecho dramático, de una revelación que tiene que ver con el diálogo entre las artes y la posibilidad que éstas proporcionan para representar la realidad. En definitiva, con el proceso ilusorio del arte.

\section{REFERENCIAS BIBLIOGRÁFICAS}

ALBARRACÍN SARMIENTO, C. (1982). «Literatura y realidad en Las babas del diablo de Cortázar». En Actas del IV Congreso Internacional de Hispanistas, E. Bustos Tovar (ed.), vol. I, 95-104. Salamanca: Universidad de Salamanca.

ASENSI, M. (2011). Crítica y sabotaje. Barcelona: Anthropos.

BAJTín, M. (1986). Problemas de la poética de Dostoievski. México D. F.: Fondo de Cultura Económica.

- (1989). Teoría y estética de la novela. Madrid: Taurus.

BOBES NAVES, M. C. (1991). Comentario semiológico de textos narrativos. Oviedo: Universidad de Oviedo.

CASETTI, F. (1996). El film y su espectador. Madrid: Cátedra.

CORTÁZAR, J. (2005). Las armas secretas. Buenos Aires: Alfaguara.

CHATMAN, S. y DUNCAN, P. (ed.) (2004). Michelangelo Antonioni. Madrid: Taschen.

DOLEZEL, L. (1986). «Semiotics of Literary Communication». Strumenti Critici 50, 5-48.

DUBOIS, P. (1986). El acto fotográfico. De la representación a la recepción. Barcelona: Paidós.

FONTCUBERTA, J. (2010). Blow up Blow up. Cáceres: Editorial Periférica.

FONT, D. (2003). Michelangelo Antonioni. Madrid: Cátedra.

GAUDREAULT, G. y JOST, F. (1995). El relato cinematográfico. Barcelona: Paidós.

GONZÁLEZ REQUENA, J. (1995). «El paisaje: entre la figura y el fondo». Eutopías (Valencia: Episteme), 1-49. 
MAESTRO, J. G. (1997). «Sentido y transducción literaria (de M. Vargas Llosa a G. García Márquez)». En Quinientos años de soledad. Actas del congreso «Gabriel García Márquez», Anexos de Tropelías 3, T. Blesa (ed.), 553-563. Zaragoza: Universidad de Zaragoza.

PÉREZ BOWIE, J. A. (2008). Leer el cine. Salamanca: Universidad de Salamanca.

- (2010). Reescrituras fílmicas: nuevos territorios de la adaptación. Salamanca: Universidad de Salamanca.

POYATO, P. (2006). «Circuito enunciativo de agresión y mundo originario en Los olvidados de Buñuel». Pandora 6, Rupture(s) (Paris: Université Paris 8), 171-190.

POZUELO YVANCOS, J. M. (1993). Poética de la ficción. Madrid: Síntesis.

TINAZZI, G. (2005). Michelangelo Antonioni. Bilbao: Ediciones Mensajero.

VILLANUEVA, D. (2006). El comentario del texto narrativo: cuento y novela. Madrid: Mare Nostrum.

- (2008). «Autobiografía (Camilo José Cela) y biografía (Ricardo Franco) de Pascual Duarte». En El realismo y sus formas en el cine rural español, P. Poyato (ed.), 51-84. Córdoba: Ayuntamiento de Dos Torres y Diputación de Córdoba.

ZUNZUNEGUI, S. (1994). Paisajes de la forma. Madrid: Cátedra.

Recibido el 3 de febrero de 2012.

Aceptado el 28 de septiembre de 2012. 
